\title{
RAPID GROUP AND SPECIES IDENTIFICATION OF ENTEROCOCCI BY MEANS OF TESTS WITH POOLED PHAGES
}

\author{
Paula Pleceaş and H. Brandis \\ Institute of Medical Microbiolology and Immunology, University of Bonn, Germany
}

\section{Plate XXXII}

LiTrLE is known about the epidemiology of infection with group-D streptococci. One reason for this may be that, to recognise members of the species that make up this group, several tests must be performed. A rapid and simple method is needed that can be applied in the diagnostic laboratory to identify members of the group and to distinguish clearly between the most important species, Streptococcus faecalis and S. faecium.

The serological group diagnosis according to Lancefield remains the most accurate method for the classification of group-D streptococci; however, many difficulties have been met in the preparation of a potent group serum (Shattock, 1962), as well as in the extraction of the group-D antigen from the strains to be identified (Pleceass, 1970).

The cultural and biochemical tests used for the differentiation of species and varieties among the group-D streptococci were described by Deibel (1964), Hartman, Reinbold and Saraswat (1966), Facklam and Moody (1970) and Pleceaș (1970).

In 1959, Ciucă et al. demonstrated the possibility of phage-typing enterococci and the usefulness of this method for the differentiation of these streptococci. Further investigations (Baldovin-Agapi et al., 1962; Pleceaş, 1969; Brandis and Esper, unpublished) led to the assembly of a set of 20 phage preparations active on strains of $S$. faecium and $S$. faecalis. The usefulness of phage-typing of group-D streptococci has been confirmed by several authors (Nátkin, 1967; Hérmán and Hoch, 1971; Hoch and Hérmán, 1971). In the present note, we report the preliminary results of using mixtures of phages to give a group and a species diagnosis together in one test.

\section{MATERIAL AND METHODS}

Bacteriophages. Preparations of the following 20 enterococcal bacteriophages were used; the routine test dilution (RTD) of each is given in brackets: (1) Romanian phages (Pleceass,

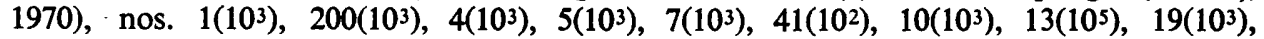
$8\left(10^{2}\right), 670(101)$, and $867\left(10^{1}\right)$; (2) phages isolated by Brandis and Esper (unpublished) from sewage, nos. $4 \mathrm{~J}\left(10^{7}\right), 4 \mathrm{D}_{2}\left(10^{5}\right), 4 \mathrm{D}_{1}\left(10^{6}\right), 16 \mathrm{D}\left(10^{6}\right), 17 \mathrm{D}\left(10^{5}\right), 24 \mathrm{D}\left(10^{3}\right), 26 \mathrm{D}\left(10^{3}\right)$, $27 \mathrm{E}\left(10^{3}\right)$. Three of the phages, namely nos. 8, 670 and 867 , are specific for $S$. faecium and the remainder for $S$. faecalis. The RTD of the phages was determined as the highest decimal dilution of the preparation that gave confluent lysis of the propagating strain of the phage.

For the group diagnosis a mixture of equal quantities of the 20 undiluted phage preparations was used. It should be noted that the final strength of the individual phages in this pool varied between an RTD of 500,000 and 0.5 , but was in most instances well in excess of 1 .

For the species diagnosis a mixture of the 17 phages specific for $S$. faecalis each diluted to a final strength of RTD $\times 1$, and a mixture of the three phages specific for $S$. faecium similarly diluted, were applied. If no reactions were obtained, the tests were repeated with pools of phage at RTD $\times 10$. Additionally, for the differentiation of $S$. faecalis, we used the following three pools of phages all at a final dilution of RTD $\times 1$ : pool no. 1, phages no. 200, 4, 5, 27E and 7; pool no. 2, phages no. $41,4 \mathrm{D}_{1}, 16 \mathrm{D}, 26 \mathrm{D}$ and $4 \mathrm{D}_{2}$; pool no. 3 , phages no. $24 \mathrm{D}, 10$,

Received 16 July 1973; revised version accepted 11 April 1974.

*Fellow of the Humboldt Foundation.

J. MED. MICROBIOL. - VOL. 7 (1974) 529 
$13,19,4 \mathrm{~J}$. In many cases this procedure allowed a subdivision of $S$. faecalis, so that for determining the phage type only the phages in one pool had to be tested separately. In this note, however, we report on the group and species diagnosis only.

Typing method. The bacterial strains to be tested were grown in Tryptose Phosphate Broth (Difco) for 2 hours at $37^{\circ} \mathrm{C}$ and afterwards seeded by flooding plates of a solid medium consisting of Tryptose Phosphate Agar (Difco) with the addition of $5 \%$ bovine serum. After removing the excess of fiuid and drying the plates, drops of the phage mixture were applied at predetermined positions on the plates (fig. 1). The plates were incubated at $37^{\circ} \mathrm{C}$ and read the next day both with the naked eye and with a magnifying glass.

Streptococcal strains. A total of 223 members of the different species and varieties of group-D streptococci were phage-typed. Among them were 175 cultures that had been

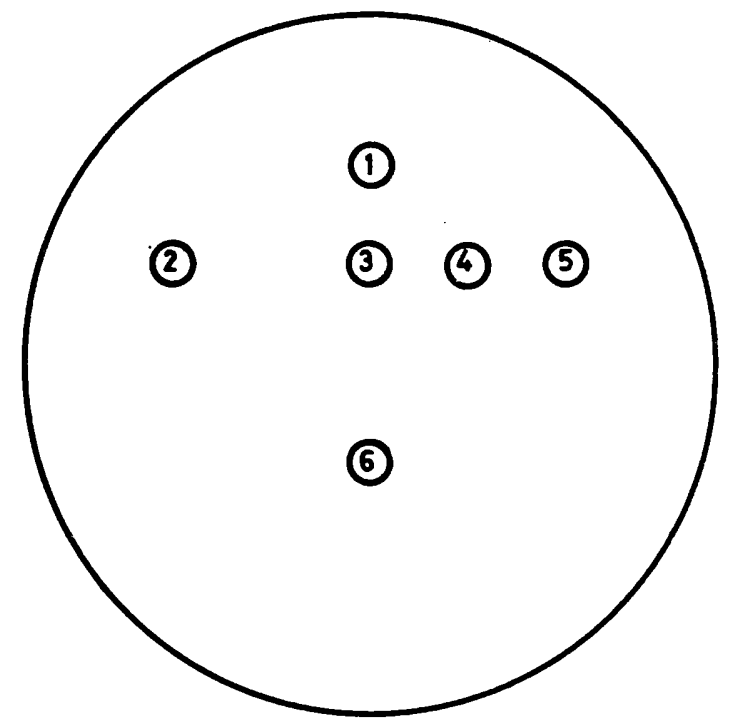

FIG. 1.-Scheme of arrangement of phages on the typing plate: $1=$ pool of all 20 phages for group diagnosis; $2=$ pool of $17 S$. faecalis phages; $3,4,5=$ sub-pools of $S$. faecalis phages (nos. $1-3$, see text); $6=$ pool of three $S$. faecium phages.

isolated from human pathological specimens or from water or animals; of these, 122 were accurately identified by biochemical methods and serological grouping but the remainder were freshly isolated strains subjected to a less detailed examination (growth characteristics and haemolysis) and identified mainly by tests with pooled phages. We also phage-typed 48 culture-collection strains, received from the National Collection of Type Cultures (NCTC), London, the Cantacuzino Institute, Dr P. A. Hartman, Dr M. Elisabeth Sharpe, Professor O. Mundt and Dr D. G. Smith.

Other cocci examined included one representative each of streptococci of groups A, B, C, D, E, F, G, H, K, L, M, N, O, P, Q, R and S (from the NCTC), two strains each of S. mitis, $S$. salivarius and $S$. uberis, and one each of $S$. milleri, $S$. mutans and Aerococcus viridans (from the NCTC or Dr Hartman).

Biochemical testing was done by standard methods.

\section{RESULTS AND DISCUSSION}

Of the 122 strains that had been fully characterised biochemically, 47 were $S$. faecalis, 11 S. faecalis var. zymogenes, 26 S. faecalis var. liquefaciens and 28 S. faecium. All except four were lysed by the 20-phage "enterococcal" pool (table 1 ). The results of testing with the separate pools of faecalis and faecium phages (at RTD $\times 1$ ) in most cases gave a clear differentiation between the two species; but these tests were less sensitive, and $24 S$. faecalis cultures 


\section{IDENTIFICATION OF ENTEROCOCCI}

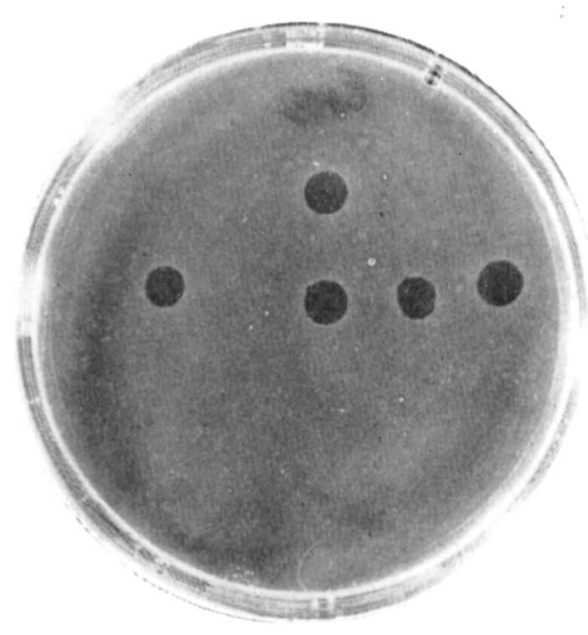

FIG. 2.-S. faecalis var. liquefaciens (no. NCTC 8175 ) giving reactions with group pool and all $S$. faecalis pool phages.

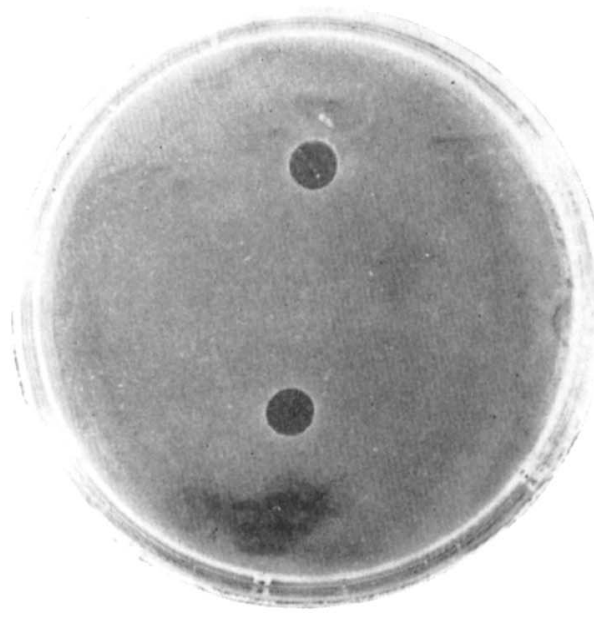

FIG. 3.-S. faecium (no. S58) giving reactions with group pool and $S$. faecium pool phages. 
had to be re-typed with more concentrated phage-pools $(\mathrm{RTD} \times 10)$ to obtain not only a group but also a species diagnosis. Figs. 2 and 3 illustrate representative examples of typing plates.

TABLE I

Identification of enterococci by means of tests with pooled phages

\begin{tabular}{|c|c|c|c|c|c|}
\hline & & & Number & strains & \\
\hline & & & & ysed by the & \\
\hline & strains & examined & $\begin{array}{l}\text { 20-phage } \\
\text { entero- }\end{array}$ & $\begin{array}{l}\text { 17-phage } \\
\text { faecalis }\end{array}$ & $\begin{array}{l}\text { 3-phage } \\
\text { faecium }\end{array}$ \\
\hline by full & $\begin{array}{l}\text { Streptococcus } \\
\text { faecalis } \\
\text { S. faecalis var. }\end{array}$ & 47 & 44 & 44 & 0 \\
\hline $\begin{array}{l}\text { set of } \\
\text { tests }\end{array}$ & $\begin{array}{l}\text { zymogenes } \\
\text { S. faecalis var. }\end{array}$ & 11 & 11 & 11 & $\mathbf{0}$ \\
\hline as & $\begin{array}{l}\text { liquefaciens } \\
\text { S. faecium }\end{array}$ & $\begin{array}{l}36 \\
28\end{array}$ & $\begin{array}{l}36 \\
27\end{array}$ & $\begin{array}{r}36 \\
0\end{array}$ & $\begin{array}{r}0 \\
27\end{array}$ \\
\hline by short & S. faecalis & 37 & 37 & 37 & 0 \\
\hline $\begin{array}{l}\text { tests } \\
\text { as }\end{array}$ & $\begin{array}{l}\text { s. faecium } \\
\text { S. }\end{array}$ & $\begin{array}{r}14 \\
2\end{array}$ & $\begin{array}{r}14 \\
2\end{array}$ & $\begin{array}{r}14 \\
0\end{array}$ & $\begin{array}{l}0 \\
2\end{array}$ \\
\hline
\end{tabular}

TABLE II

Lysis of standard strains in the tests with pooled phages

\begin{tabular}{|c|c|c|c|c|}
\hline \multirow[b]{3}{*}{ Species and variety } & \multicolumn{4}{|c|}{ Number of strains } \\
\hline & \multirow[b]{2}{*}{ examined } & \multicolumn{3}{|c|}{ lysed by the } \\
\hline & & $\begin{array}{l}\text { 20-phage } \\
\text { entero- } \\
\text { coccal } \\
\text { pool }\end{array}$ & $\begin{array}{c}\text { 17-phage } \\
\text { faecalis } \\
\text { pool }\end{array}$ & $\begin{array}{c}\text { 3-phage } \\
\text { faecium } \\
\text { pool }\end{array}$ \\
\hline \multirow[t]{2}{*}{$\begin{array}{l}\text { Streptococcus faecalis } \\
\text { S. faecalis var. zymogenes } \\
\text { S. faecalis var. liquefaciens } \\
\text { S. faecium } \\
\text { S. faecium var. durans } \\
\text { S. faecium var. casseliflavus } \\
\text { S. bovis } \\
\text { S. equinus } \\
\text { Motile enterococci } \\
\text { Streptococci, groups A-S } \\
\text { "Viridans" and non- } \\
\text { haemolytic streptococci" }\end{array}$} & $\begin{array}{r}8 \\
1 \\
1 \\
10 \\
4 \\
4 \\
6 \\
9 \\
5 \\
17\end{array}$ & $\begin{array}{l}7 \\
1 \\
1 \\
5 \\
3 \\
3 \\
3 \\
2 \\
0 \\
0 \\
0\end{array}$ & $\begin{array}{l}7 \\
1 \\
1 \\
0 \\
0 \\
0 \\
0 \\
0 \\
0 \\
0\end{array}$ & $\begin{array}{l}0 \\
0 \\
0 \\
5 \\
3 \\
3 \\
2 \\
0 \\
0 \\
0\end{array}$ \\
\hline & 10 & 0 & 0 & 0 \\
\hline
\end{tabular}

* Includes one strain of Aerococcus viridans.

Because the 20-phage test appeared to be a reasonably good method for identifying enterococci isolated in the clinical laboratory, we examined another 53 freshly isolated strains.

J. MED. MICROBIOL.-VOL. 7 (1974 
All were lysed by the pooled phages. In all, 171 of $175(97 \cdot 7 \%)$ of the strains were lysed by this method.

The results of testing the culture-collection strains with pooled phages given in table II were not similarly satisfactory. All except one of the $S$. faecalis strains, but only eight of 14 strains of $S$. faecium or $S$. faecium var. durans were lysed. This suggests that our faecium phages, though apparently adequate for the recognition of strains isolated in clinical practice, may need some additions. Three of four $S$. faecium var. casseliflavus and two of six $S$. bovis strains were lysed, but not any of $S$. equinus or the motile enterococci. That indicates that we have not yet available phages for $S$. equinus, $S$. bovis and the motile enterococci. The streptococci of serological groups A-S and the "viridans" and non-haemolytic streptococci were completely resistant to lysis by our phages.

In conclusion, the tests with pooled phages seem adequate for the identification only of enterococci and give the possibility of a distinction between $S$. faecalis and $S$. faecium, especially of human origin, together in one test without technical difficulties. Subsequent studies aimed at obtaining new phage preparations active on $S$. faecium as well as on the remaining species of group-D streptococci will help to improve the method and perhaps to extend it, from the principal species of enterocococci ( $S$. faecalis and $S$. faecium) to all the group-D streptococci.

\section{SUMMARY}

Preliminary observations are reported on the use of phage pools for the group and species diagnosis of enterococci together in one test. Three principal pools were used, namely: (1) pool of 20 phages for group diagnosis, (2) pool of 17 phages for Streptococcus faecalis species diagnosis and (3) pool of 3 phages for $S$. faecium diagnosis.

By this method, 171 of 175 strains of enterococci isolated in the clinical laboratory $(97.7 \%)$ were identified. A collection of standard group D strains showed different sensitivities according to species. The separate pools of phages for $S$. faecalis and for $S$. faecium can be used to distinguish between members of these two species, but this test is at present rather less sensitive than the test with the 20-phage pool.

We thank Dr M. T. Parker (London), Dr D. G. Smith (London), Dr Paul Hartman (Ames, Iowa, U.S.A.), Professor O. Mundt (Knoxville, Tenn., U.S.A.), and Dr C. Kraseman (Bonn, Germany) for their kindness in sending us the strains and for useful suggestions.

\section{REFERENCES}

Baldovin-Agapi, C., Balteanu, E., Mihalco, F., Beloiv, I. and Pleceaș, P. 1962. Systèmés phage-bacterie chez les streptocoques du groupe D Lancefield. Archs. roum. Path. exper. Microbiol., 21, 385.

Ciucă, M., Baldovin-Agapi, C., Minalco, F., Beloru, I., ANd Caffe, I. 1959. Eco-systèmes phages-streptocoques. Essais de lysotypie des streptocoques du groupe D. Archs. roum. Path. expèr. Microbiol., 18, 519.

DeIBel, R. H. 1964. Group D streptococci. Bact. Rev., 28, 330.

FACKLAM, R. R. AND Moody, M. D. 1970. Presumptive identification of group D streptococci: the bile esculin test. Appl. Microbiol., 20, 245.

Hartman, P. A., Reinbold, G. W. and Saraswat, D. S. 1966 . Media and methods for isolation and enumeration of the enterococci. Adv. appl. Microbiol., 8, 253.

HÉRMÁN, G. AND Hoch, V. 1971. Phage typing of D-group streptococci. II. Isolation of supplementary phages for classification of enterococci untypable with Roumanian phages. Acta Microbiol., Hung., 18, 101.

Hoch, V. AND Hérmán, G. 1971. Phage typing of D-group streptococci. I. Typing of enterococci with Roumanian phages. Acta microbiol. Hung., 18, 95.

Kandler, O., SchleIFer, K. H. AND DaNDl, R. 1968. Differentiation of Streptococcus faecalis Andrewes and Horder and Streptococcus faecium Orla-Jensen based on the amino-acid composition of their murein. J. Bact., 96, 1935. 
NÁTKIN, E. 1967. Isolation and host range of bacteriophages active against human oral enterococci. Archs oral Biol., 12, 669.

Pleceaș, P. 1969. Lysotypie des streptocoques du groupe D. Arch. roum. Path. expèr. Microbiol., 28, 1027.

Pleceaş, P. 1970. Die Diagnostik der D-Streptokokken (Enterokokken). Zentbl. Bakt. ParasitKde., I. Abt. Orig., 214, 130.

Shattock, P. M. F. 1962. Enterococci. In Chemical and biological hazards in food. International Symposium on food protection, edited by J. C. Ayres, A. A. Kraft, H. E. Snyder and H. W. Walker, Ames, Iowa, p. 303. 